\title{
The Recharge Potential of Groundwater in the Mokonde Community in Southern Sierra Leone
}

\author{
Abubakarr S. Mansaray¹, Alhaji B. Gogra1, Abu-Bakarr S. Massaquoi², \\ Josephus F. Borsuah'1 \\ ${ }^{1}$ Chemistry Department, Njala University, Njala, Sierra Leone \\ ${ }^{2}$ UNDP's GEF/SGP, Freetown, Sierra Leone \\ Email: absmansaray@gmail.com
}

Received 7 October 2015; accepted 13 November 2015; published 16 November 2015

Copyright (C) 2015 by authors and Scientific Research Publishing Inc.

This work is licensed under the Creative Commons Attribution International License (CC BY). http://creativecommons.org/licenses/by/4.0/

Open Access

\section{Abstract}

Understanding the hydrologic budget is crucial in planning for community based water supply. The water budget includes rainfall intensity, groundwater recharge, interception, evapotranspiration, and surface runoff. The percentage of rain going to recharge groundwater, rivers, and lakes is very important from the standpoint of human water consumption and ecosystems service. The objective of this work is to determine the recharge potential of groundwater in the Mokonde Community, Southern Sierra Leone. The community is dependent on wells as the main source of domestic water supply. This research need was born out of the absence of available data to show the relationship between rainfall amounts and groundwater recharge in the study area. In this study we monitored groundwater in a well at the United Methodist Church (UMC) compound at Ngegba Street. Automatic water logging devices were deployed to take readings in water level fluctuations every 15 minutes. Monitoring continued throughout the hydrological year of Sierra Leone. A rain gauge was deployed at neighboring UMC Primary School, and daily rainfall records taken at 9:00 a.m. Our team members also deployed at the well on a daily basis to collect data on abstraction of water. The results revealed, through a 29-year rainfall data and the Specific Yield, that $1170 \mathrm{~mm}$ of rainfall $(48 \%)$ was the maximum potential of rainfall that would make groundwater a convenient source of water supply in the area. This demand was higher with the recent 1-year rainfall data. Increase in settlement had likely led to reduction in pervious area, and hence more and more rainfall needed for recharge. The time it took for maximum recharge (4 weeks) was shorter than that for maximum discharge (28 - 30 weeks). Groundwater flowed southwards towards the Gbengitay stream, which drained into the Tia River. These results would inform first step in delineating the water balance in the study area. Future studies could include the quality aspect, stream/river flow, interception and evapotranspiration. These pieces of information are required to help informed decision for water security. 


\section{Keywords}

\section{Groundwater, Recharge, Discharge, Rainfall, Pervious Area, Specific Yield}

\section{Introduction}

The Mokonde Community in southern Sierra Leone is dependent on wells as the main source of domestic water supply. Preliminary survey results reveal that the wells are shallow and hence it is easily accessible for water, particularly in the rainy season. Additionally, the consumers agree that the water is palatable in terms of color, taste and odor. In essence, therefore, a water security project that focuses on improving groundwater resources in this community will sound meaningful to the consumers. However, sustainable groundwater use plans must follow from understanding availability in space and time as well as quality. This work seeks to delineate the minimum amount of rain required to recharge the groundwater resources in the area. Additionally, the rate of discharge and its underlying factors are studied.

A study in the Upper Nile Basin shows that observed recharge of groundwater is better related to peak rainfall events. The data inform the simulation of climate change issues relating to groundwater availability [1]. However, rainfall-recharge relationship depends on several other factors. When rain falls, it undergoes a number of processes, depending on the landscape, soil type, and geology of the area. Some of the rainwater infiltrates and absorbs into the soil. This water is available for plants to take up through which they get their nutrient supply. The water, known as green water, is then transpired into the atmosphere [2]. In addition to transpiration, certain percentages of rainwater as intercepted rainwater and surface water will evaporate back into the atmosphere. A small portion will remain available for groundwater recharge [3].

Base flow and abstraction for domestic use are the two discharge determinants considered in this study. According to the American Ground Water Trust [4], base flow is the principal source of water in rivers during dry periods. Rosen and Vincent [5] estimated, based on series of studies reviewed, a minimum of 10 liters per person per day as the average quantity of water used by people in rural areas of sub Saharan Africa.

Current data are not available to show the relationship between rainfall patterns and groundwater recharge in the study area. Even though there is the obvious expectation of groundwater levels during the dry and rainy seasons, understanding the fluctuations in increase or decrease, as a function of daily rainfall, abstraction and base flow, will be useful in water security planning.

The need for this work is obvious considering seasonality issues of groundwater availability in the area. In the dry season, most of the dug wells become dried up. This poses the burden of hiking long distances to fetch water, creating both economic and social problems for the community [6]. Overcoming this challenge requires a better understanding of the amount of groundwater supplied in the rainy season compared to the amount required throughout the year. This will help inform Best Management Practices (BMPs) in terms of priority setting, choosing alternatives, technology development, and resource mobilization. This research therefore seek to answer the following questions:

- How much rain does the study area receive per year?

- What is the total amount of rainfall required to fully recharge groundwater in the area?

- How long does it take to achieve this potential?

- What factors affect the fate of this potential?

The work has an objective of providing information on the recharge potential of groundwater and retention time in the UMC well at Ngegba Street. The expectation is to set the stage for utilization of information inferred from the study: managing the factors that determine the fate of ground water as regards improving and sustaining availability and quality.

\section{Materials and Methods}

\subsection{Description of the Study Area}

The Mokonde Community is located in Kori Chiefdom in Moyamba District, Southern Sierra Leone (Figure 1); it is situated southeast of contiguous Njala University, Njala Campus. The Tia River is located about $3 \mathrm{~km}$ west 
of the community. Common land use practices include production of tropical crops like cassava, sweet potato, palm oil and the country's staple food, rice; petty trading, and small scale fishing are also prominent.

The community depends largely on the use of groundwater in the form of hand dug wells. Water scarcity in the dry season burdens the community with long hours of looking for alternative sources such as the Gbengitay stream, which is located south of the community, other wells that do not run dry, the Tia River, and expensive sources: sachet and bottled water.

Mokonde experiences dry season which lasts from late November to April. The temperature is high at an average of $30^{\circ} \mathrm{C}$. The rainy season lasts from May to Mid-November with relatively high humidity and heavy down pour of rain.

This community is growing rapidly following the return of Njala University at the end of the nation's civil war in the 1990s. The nation's 2004 population and housing census puts the total population at 2879.

\subsection{The Observation Well and Rain Gauge Site}

The observation well used for hydrological monitoring is situated at Ngegba Street in Mokonde. The rain gauge site was situated at nearby UMC Primary School. Figure 2 shows map of Moyamba District geo-referencing the study area.

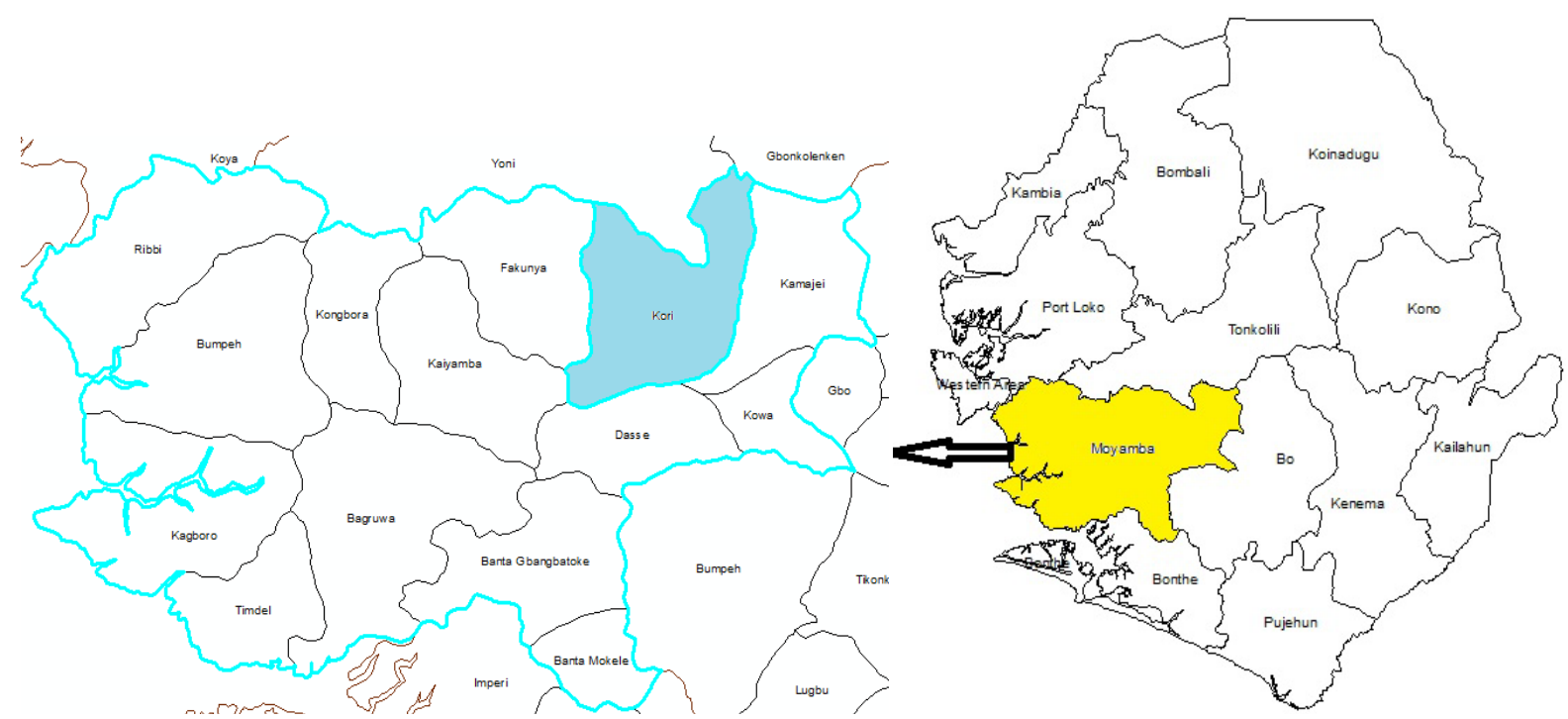

Figure 1. Map of Sierra Leone showing Moyamba District (Highlighted Yellow) and Kori Chiefdom (Highlighted Blue).

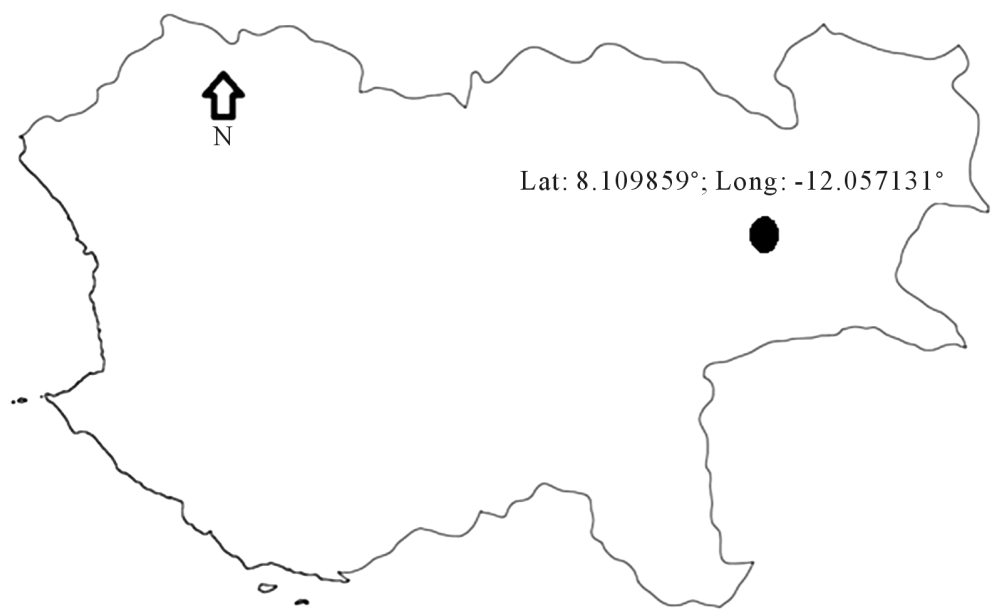

Figure 2. Map of Moyamba District showing location of study area. 


\subsection{Materials and Equipment}

\subsubsection{Win-Situ Aqua Logger}

This comprises a Rugged Troll and Rugged Barro, both easy-to-use software based aquatic data logging instruments. The Rugged Troll was used to measure the depth to water below ground level while the Rugged Barro was used to measure air pressure above the water in the well. Both instruments have completely sealed bodies that contain an absolute (non-vented) pressure sensor, temperature sensor, real-time clock, microprocessor, lithium battery, and internal memory. The Rugged TROLL 100 is designed to hang by a back-shell hanger from a suspension wire.

\subsubsection{Rain Gauge}

The rain gauge is made of plastic with a total capacity of $225 \mathrm{~mm}$. It consists of an outer cylinder within which there is a smaller diameter measuring cylinder marked in $0.5 \mathrm{~mm}$ units up to $25 \mathrm{~mm}$. It is placed on a level ground, surrounded by low vegetation, located in an open ground with a distance greater than twice the height of the fence protecting it. It is mounted $1.2 \mathrm{~m}$ above ground level with the rim of the funnel above the height of the post.

\subsection{Abstraction of Water from the Monitoring Well}

Residents within a 1-mile radius depend on the UMC well for their domestic water supply; there is water in the well throughout the year. The well is crowded at two peak periods, 07:00 - 09:00 and 17:00 - 19:00, every day particularly in the dry season. These peak periods are the most convenient for children and women who form the majority of people abstracting water from the well. The children are busy with school or farming while the women go trading or farming during the day.

Our team members deployed at the monitoring site during the two peak periods on a daily basis, from April to August 2014. Members of the community fetched water in a 2.5 gallon $\left(0.01 \mathrm{~m}^{3}\right)$ container tied to a rope long enough to reach the water in the well. They fetched water by turn, on a first come first serve basis, to fill their containers and use for domestic purposes. The volume of water abstracted per day was recorded in a spreadsheet as shown in Table 1.

Table 1. Entry spreadsheet for water abstracted from the well per day.

\begin{tabular}{|c|c|c|c|c|c|c|}
\hline \multirow{3}{*}{ Date } & \multicolumn{2}{|c|}{ Number of 2.5 Gallons drawn } & \multicolumn{4}{|c|}{ Time } \\
\hline & \multirow{2}{*}{ Morning } & \multirow{2}{*}{ Evening } & \multicolumn{2}{|c|}{ Morning } & \multicolumn{2}{|c|}{ Evening } \\
\hline & & & Start & End & Start & End \\
\hline
\end{tabular}

\subsection{Deployment of Monitoring Equipment}

The win-situ rugged troll picked pressure signals in the water column and the software translated those pressure changes in the water column (in relation to pressure of the overlying air) into water levels below ground (in meters). The instrument was programmed to take readings every 15 minutes; the sensor detects changes in barometric pressure and stores the records in a built-in memory. At the end of every month the recorded datasets are downloaded and exported as csv files for data analysis, and the instrument redeployed to continue in-situ read- 
ings of water level fluctuations.

Our team members visited the rain gauge site at 9:00 a.m. every morning, to measure the amount of rainfall from rain events on the previous day. All the water captured in the outer container and the central graduated cylinder was poured into a separate container taking care to avoid spillage of water. The amount of water was then measured in the central graduated cylinder. Care was taken to avoid overflow. The measured water was kept in a separate container so if an error occurred the process could be repeated. Large volumes were measured in bits, noting each measurement on the record sheet until all the water was measured.

\subsection{Determination of Recharge Potential Using the Specific Yield Method}

The Specific Yield method was used to determine recharge potential in the study area. According to Healy and Cook [7], the method is based on the premise that rise and fall in groundwater levels are due to recharge water arriving at the water table; the method is widely used and does not depend on the physical, chemical and biological properties of the landscape. The recharge $(R)$ is calculated as $R=S_{y} \Delta h$. Where $S_{y}$ is specific yield, $\Delta h$ is change in water-table height. The method is useful with the presumption that Water Table Fluctuation (WTF) in a well reflects the integrated effects in the entire area stretching over several acres [8]. The method being applicable to unconfined aquifers and is best when applied to shallow water tables [7], makes it suitable for our well in question.

The Volume-Balance method [7] was used to determine the specific yield. We utilized the water budget of the well to develop the relationship $S_{y}=V_{c} / V_{w}$; where $V_{w}$ is the maximum volume of water the well can hold per hydrological year and $V_{c}$, the minimum volume. The timeframe (hydrological year) was meant to achieve maximum specific yield [9] giving that this study aimed at establishing the recharge potential of the area.

\section{Results and Discussions}

\subsection{Groundwater Recharge}

\subsubsection{Rainfall Trends}

The month of August recorded the heaviest rainfall events in the study area, as confirmed in the daily rainfall data collected. The daily average of $14.9 \mathrm{~mm}$ (Figure 3) showed there was enough rain to enhance recharge, with reference to a threshold of $10 \mathrm{~mm} \mathrm{day}^{-1}$ [1]. The other months in the rainy season had several days with rainfall amounts that approximate to this threshold. The problem then is that the water levels drop as we enter into the dry season, probably resulting from base flow and daily abstraction by people: rainfall becomes minimal; discharge becomes greater than recharge [10].

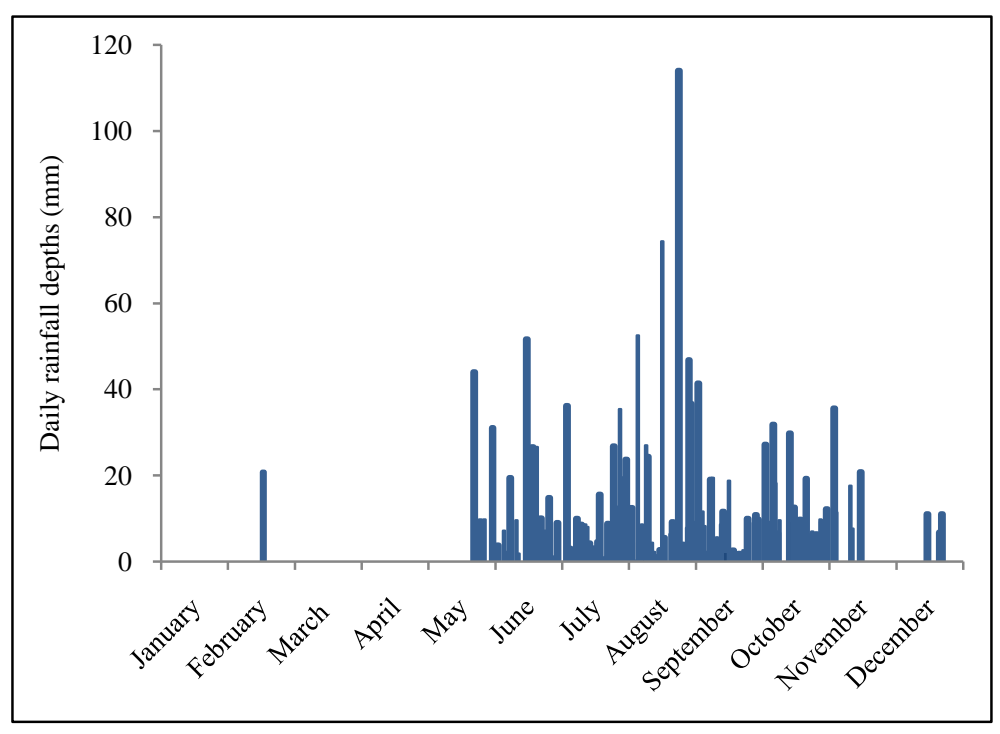

Figure 3. Daily rainfall (mm) in the study area. 
Figure 4 shows a strong relationship between recharge and peak daily rain events. Looking at the results however, recharge response to rainfall is not necessarily due to peak rain events alone. Upstream recharge might be transporting previous cumulative rainwater downstream, into the well. This is clarified by the retention time, abstraction, and seasonality.

Figure 5 presents two rainfall periods: 1951-1980 and 2013-2014; long-term and short-term monthly rainfall trends, respectively. The annual record of rainfall revealed a total of about $1637 \mathrm{~mm}$ in the short term and 2424 $\mathrm{mm}$ in the long term. How much of this goes to recharge groundwater forms the core of this study. In a tropical Malaysia study [11], it was observed that precipitation translated into to $12 \%$ as recharge, $32 \%$ as surface run off, and $56 \%$ as evapotranspiration. Considering the comparative tropical area to our study area, $12 \%$ of $1637 \mathrm{~mm}$ or $2424 \mathrm{~mm}$ would amount to $196 \mathrm{~mm}$ or $291 \mathrm{~mm}$, respectively, of rainfall requirement for groundwater recharge in the area under review. This threshold, however, needs confirmation in order to better inform BMPs for water security planning. The specific yield method was utilized for this clarification and results are discussed in section 3.1.2.

\subsubsection{Specific Yield Method}

The automatic logging device recorded water level readings in the monitoring well, every 15 seconds, from December 2013 to August 2014. This period included the two seasonal peaks: July-August in the rainy season and March-April in the dry season. Hence Sierra Leone's hydrological year was covered in this study. The change in depth to water from the first to the last sampling week (Figure 6) was designated as change in height $(\Delta h)$. The following calculations were done to determine the recharge potential; the dimensions of the well approximate to a cylindrical shape:

Diameter of the well $=0.50 \mathrm{~m}$;

Maximum depth of water in the 8-month period $=(10.00-2.00) \mathrm{m}=8.00 \mathrm{~m}$;

Minimum Depth of water in the 8-month period $=(10.00-8.50) \mathrm{m}=1.50 \mathrm{~m}$;

Maximum volume of water in the well $\left(V_{m}\right)=\pi(0.50 / 2)^{2} * 8.00=1.57 \mathrm{~m}^{3}$;

Minimum volume of water in the well $\left(V_{c}\right)=\pi(0.50 / 2)^{2} * 1.50=0.29 \mathrm{~m}^{3}$;

Specific Yield $\left(S_{y}\right)=V_{m} / V_{c}=0.29 \mathrm{~m}^{3} / 1.57 \mathrm{~m}^{3}=0.18$;

From $R=S_{y} \Delta h$, the recharge potential is $1.17 \mathrm{~m}(1170 \mathrm{~mm})$.

According to the calculation results, $1170 \mathrm{~mm}$ of rainfall, would enhance maximum recharge of groundwater in this area, with a specific yield of 0.18 . Considering the long term, more reliable annual total of $2424 \mathrm{~mm}, 48 \%$ of rainfall would potentially recharge groundwater at a level that makes groundwater supply convenient for the community. The remaining $52 \%$ is available for interception, evapotranspiration, and surface runoff. This area is

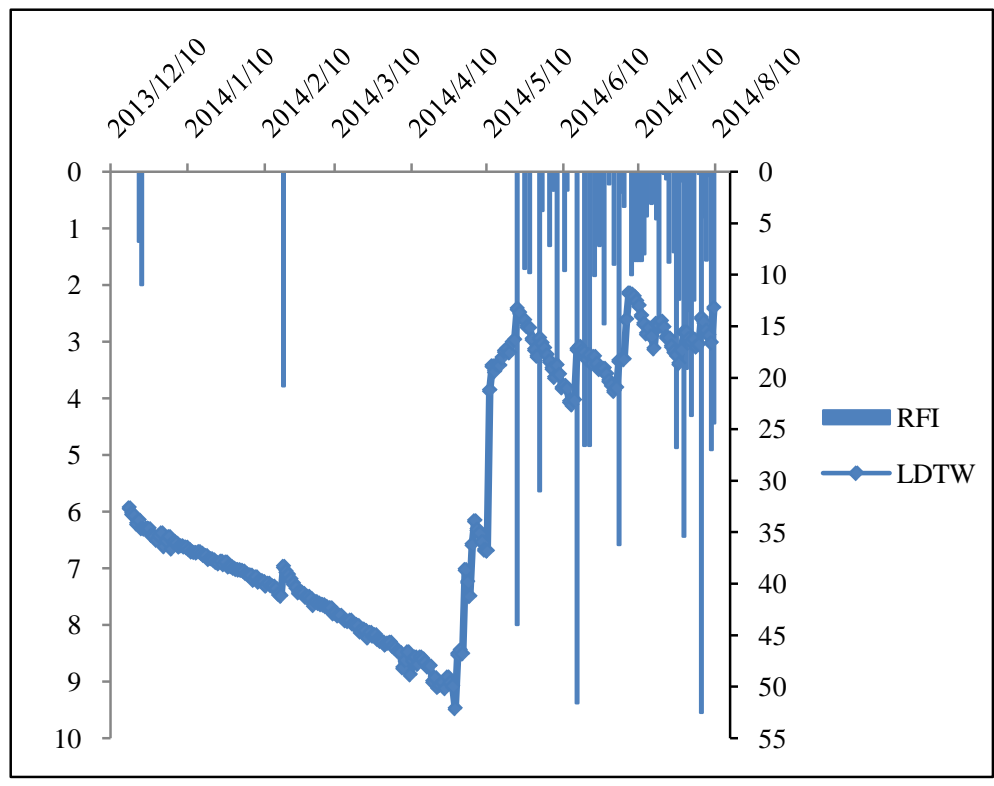

Figure 4. Rainfall intensity (RFI in mm) and level depth to water (LDTW) in the well. 


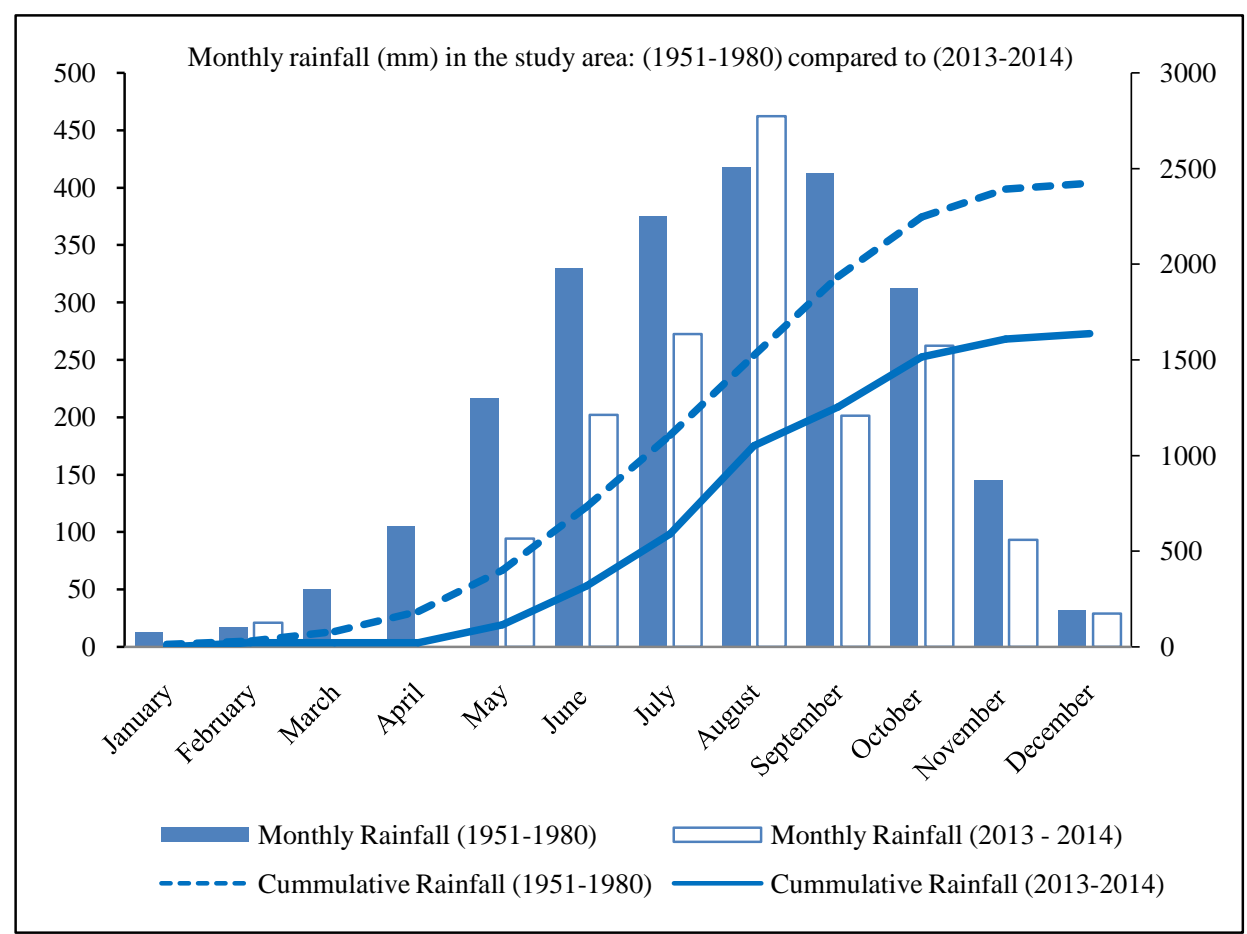

Figure 5. Rainfall records in the study area: 1951-1980 and 2013-2014.

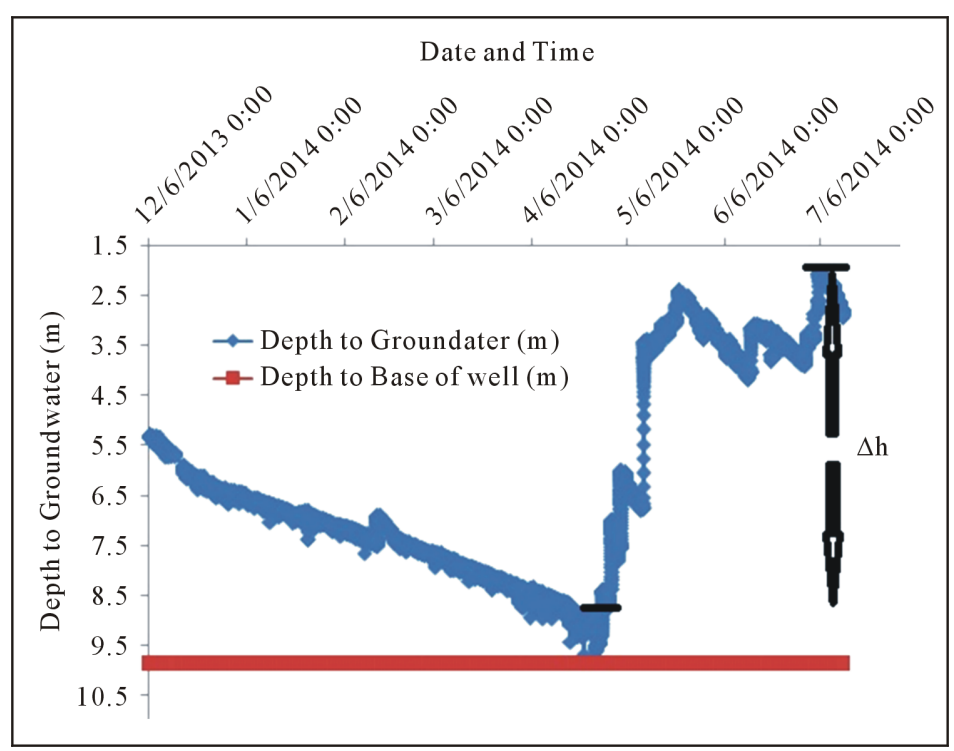

Figure 6. Spatial and temporal fluctuations of groundwater in the monitoring well.

characterized by vegetation cover and a lot of pervious land. However, increase in population and, hence impervious area could shrink this potential. Another important constraint to the utility of this potential could be the seasonality of the area. Rainfall ceased for six months, recharge dropped whilst discharge continued throughout the year. In addition, the rainfall total recorded during this study revealed a higher recharge demand (71.5\%). If rainfall intensity was dropping with time, groundwater use might be seriously constrained in the future. However, confirmation through long term rainfall monitoring was a limitation. For the moment BMPs could involve creating a balance between retention time and base flow, so as to enhance sustainable stream/river recharge, human consumption and subsurface ecology. 


\subsection{Groundwater Discharge}

\subsubsection{Abstraction of Water from the Monitoring Well}

The maximum volume of water abstracted on the 2nd of May was $5.0 \mathrm{~m}^{3}(5000 \mathrm{~L})$ and the minimum volume abstracted in a number of days was $0.3 \mathrm{~m}^{3}(300 \mathrm{~L})$. What drove the rise or fall in the frequency of visits, and the number of people visiting to fetch water was beyond the scope of this work. According to the residents, there is an inverse relationship between rainfall and abstraction of water from the well. Increase in demand resulting from less and less rainfall is clearly reflected in Figure 7: less and less people abstracted water from the well as we entered into the peak rainy season.

The volume of water collected per day was cumulated over the monitoring period. Between late April and mid-August, a total $1700 \mathrm{~m}^{3}(1,700,000 \mathrm{~L})$ of water was abstracted from the well. Thus an average of $1.6 \mathrm{~m}^{3}$ $(1600 \mathrm{~L})$ of groundwater was abstracted from the well per day. This average was higher in the dry season, giving that demand increases during the period. In March and April, draw down brought the water to the asymptotic level of $8.5 \mathrm{~m}$ below ground (Figure 6). The water was very small and muddy. The well was locked and allowed to recharge for several hours before the community was allowed to abstract again.

\subsubsection{Base Flow}

The depth to water below ground of three additional wells was monitored to help determine the direction of groundwater flow. Wells became shallower in moving from Njala campus (Florence Carew Well) through pa Mornya's compound into the Gbengitay stream further south which flowed into the Tia River. Hence groundwater flowed southwards (Figure 8). Water level below ground became deeper in the dry season; this probably contributed to low stream flows as the shallow wells that empty into streams got dried up.

The southward direction of flow is shown in Figure 9; we observed that the rate of recharge was faster than that of discharge. The slow pace in base flow made a good promise for groundwater use. It took about 28 - 30 weeks for the wells to get to their deepest points with the least volume of water, while it took about 4 weeks to recharge. When recharged, fluctuations in depth set in until the rainy season peaked. However, the fluctuations were not large as to impeding availability during the wet season peaked. Currently, groundwater availability is largely dependent on base flow, abstraction rates, and rainfall intensity. Considering the current trend in land use, future concerns could include an increase in impervious areas. The rush in purchase of land will see expansion in the village size and hence construction of more houses. Njala University is also expanding and this might put a pressure on land availability, vegetation cover, and hence the recharge potential.

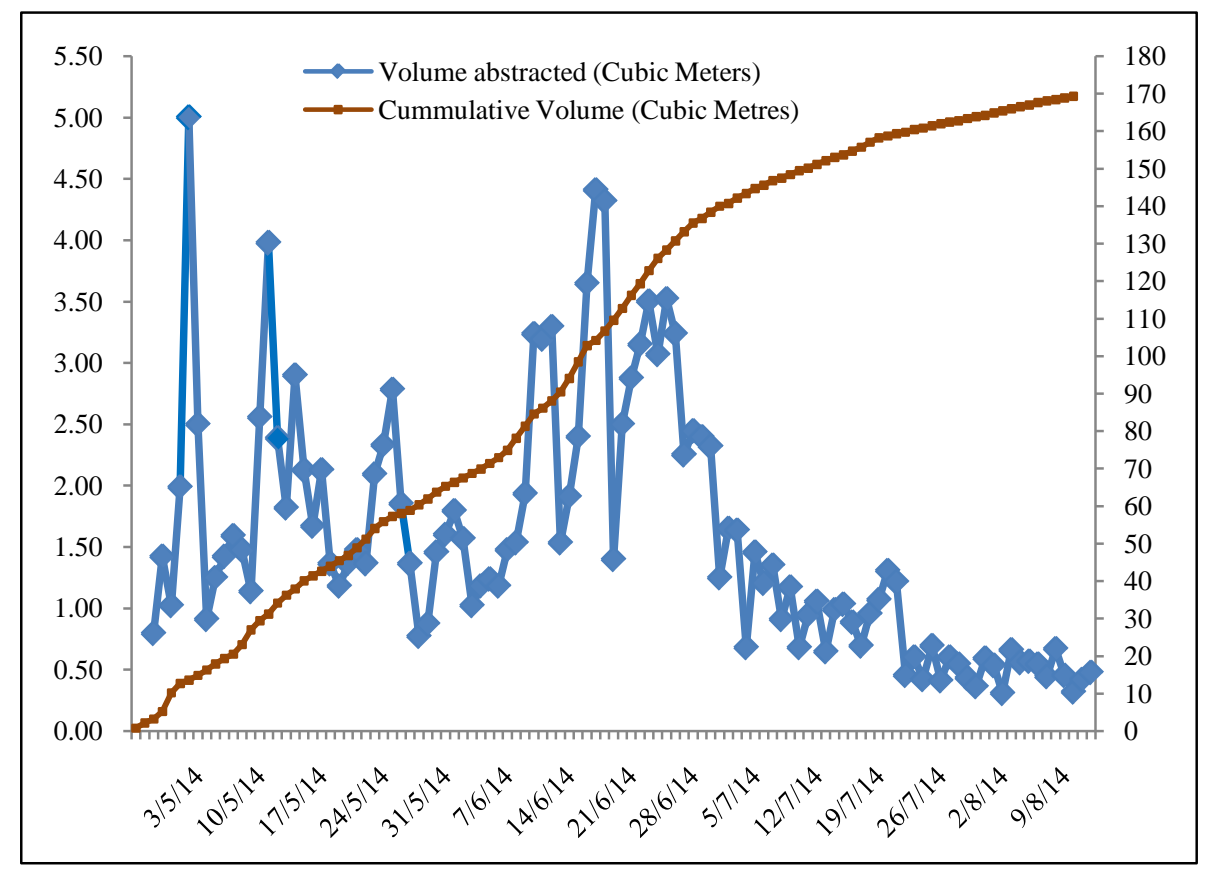

Figure 7. Volume of water abstracted from the well per day. 


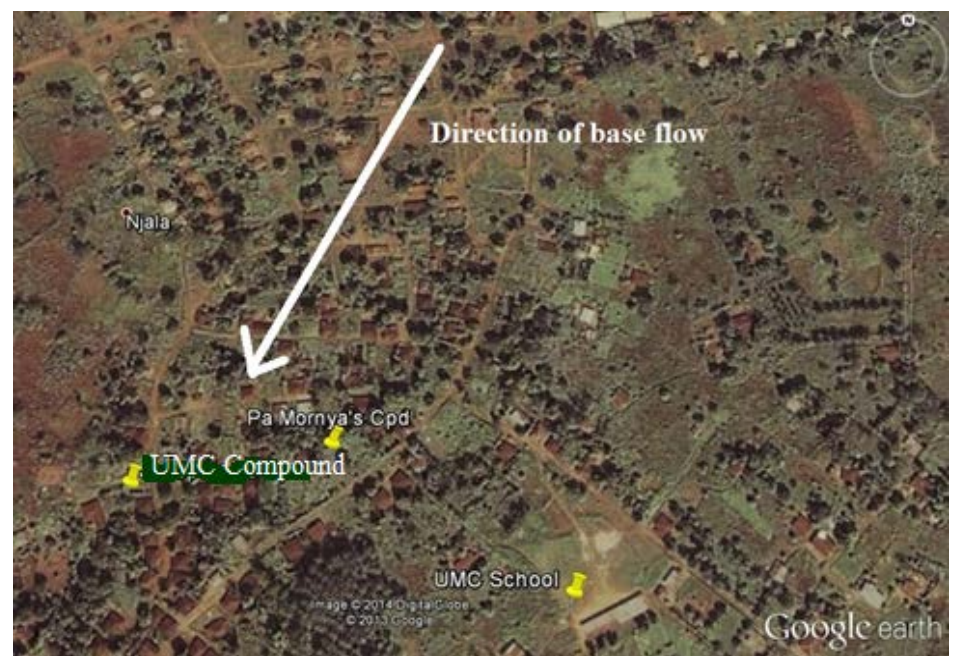

Figure 8. Direction of base flow.

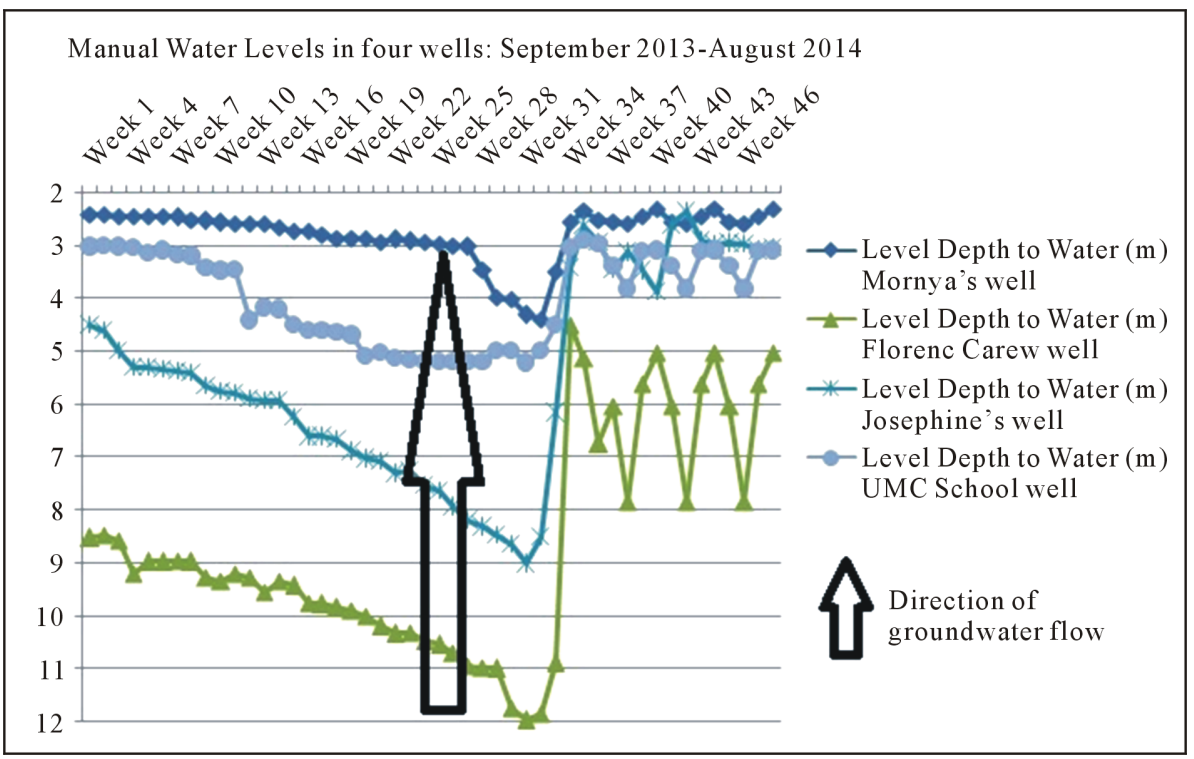

Figure 9. Direction of groundwater flow.

\section{Conclusions}

The objective of this study was to delineate the groundwater recharge potential in the Mokonde Community. The study included rainfall monitoring and also retention time and rate of discharge in the monitoring well. The rationale was to use the outcome of this study as a first step in accounting for the water balance in the study area. This would hopefully help informed decision making to enhance BMPs that would lead to water security.

Data gathering was done by the use of rain gauge, water use survey, and automatic water logging devices. The datasets were used in determining recharge potential, rate of discharge and the direction of base flow. The specific yield was used to determine the recharge potential. The rate of discharge was determined by examining the retention time of water in the well. The direction of base flow was determined by comparing depth to water below ground at wells in different locations.

The results revealed that $1170 \mathrm{~mm}$ of rain could potentially go to recharge groundwater; this would bring it to a level of convenience in groundwater supply. This amount equated to $48 \%$ of rainfall in the historical records. This implied that the community would receive enough rainfall to meet the recharge potential. The community could invest in groundwater management as their main source of water supply. Worthy of note, however, was 
the increase in impervious area due to expansion in settlements. Additionally, the rainfall total in our study period was less than the historical total. If this became the trend, the recharge potential might have dropped. This was, however, subject to confirmation from further studies.

We observed that the rate of recharge was higher than the rate of discharge. It took about 28 - 30 weeks for the well to discharge to its asymptotic level, and 4 weeks to recharge. In addition, the lowest amount present spanned in a short period of time before the minimum recharge threshold became obvious. This made a good promise for planning to use groundwater as the main source of supply in the area. BMPs that would delay discharge a bit more could help achieve water security.

Well depths became shallow southwards. This meant base flow was directed towards a stream in the southwest of the village. Land use planners could use this information in locating latrines, waste disposal sites, and water treatment centers.

This study was limited to base flow and abstraction from wells to represent discharge. There might be other discharge processes to be considered in future studies. Additionally, the quality aspect would form the core of future studies. This could help in further clarifying the direction of base flow. Future studies could also include other wells for comparative analysis. Surface water discharge and evapotranspiration studies would also help clarify the recharge potential determined in this study.

\section{References}

[1] Owor, M.,. Taylor, R.G, Tindimugaya, C. and Mwesigwa, D. (2009) Rainfall Intensity and Groundwater Recharge: Empirical Evidence from the Upper Nile Basin. Environmental Research Letters, 4, Article ID: 035009. http://dx.doi.org/10.1088/1748-9326/4/3/035009

[2] USGS (2015) Infiltration-The Water Cycle. USGS.

[3] Falkenmark, M. (2006) The New Blue and Green Water Paradigm: Breaking New Ground for Water Resources Planning and Management. Water Resources Planning and Management, 132, 129-132.

[4] American Ground Water Trust (2003) Ground Water and River Flow. The American Well Owner, 3, 3.

[5] Rosen, S. and Vincent, J.R. (1999) Household Water Resources and Rural Productivity in Sub-Saharan Africa: A Review of the Evidence. Harvard Institute for International Development, Cambridge.

[6] Pickering, A.J. and Davis, J. (2012) Freshwater Availability and Water Fetching Distance Affect Child Health in Sub-Saharan Africa. Environmental Science \& Technology, 46, 2391-2397. http://dx.doi.org/10.1021/es203177v

[7] Healy, R.W. and Cook, P.G. (2002) Using Groundwater Levels to Estimate Recharge. Hydrogeology, 10, 91-109. http://dx.doi.org/10.1007/s10040-001-0178-0

[8] Maréchal, J.-C., Dewandel, B., Ahmed, S. Galeazzi, L. and Zaidi, F.K. (2006) Combined Estimation of Specific Yield and Natural Recharge in a Semi-Arid Groundwater Basin with Irrigated Agriculture. Hydrology, 329, 281-293. http://dx.doi.org/10.1016/j.jhydrol.2006.02.022

[9] Nwankwor, G.I., Cherry, J.A. and Gillham, R.W. (1984) A Comparative Study of Specific Yield Determinations for a Shallow Sand Aquifer. Groundwater, 22, 764-772. http://dx.doi.org/10.1111/j.1745-6584.1984.tb01445.x

[10] Simpson, M.J., Jazaei, F. and Clement, T.P. (2013) How Long Does It Take for Aquifer Recharge or Aquifer Discharge Processes to Reach Steady State? Hydrology, 501, 241-248. http://dx.doi.org/10.1016/j.jhydrol.2013.08.005

[11] Saghravani, S.R., Yusoff, I., Mustapha, S. and Saghravani, S.F. (2013) Estimating Groundwater Recharge Using Empirical Method: A Case Study in the Tropical Zone. Sains Malaysiana, 42, 553-560. 